University of Nebraska - Lincoln

DigitalCommons@University of Nebraska - Lincoln

Faculty Publications from the Harold W. Manter Laboratory of Parasitology

8-1-1999

\title{
Systematics of the Eucestoda: Advances Toward a New Phylogenetic Paradigm and Observations on the Early Diversification of Tapeworms and Vertebrates
}

\author{
Eric P. Hoberg \\ United States Department of Agriculture, Agricultural Research Service, geocolonizer@gmail.com \\ Scott Lyell Gardner \\ University of Nebraska - Lincoln, slg@unl.edu \\ Ronald A. Campbell \\ University of Massachusetts - Dartmouth, rcampbell@umassd.edu
}

Follow this and additional works at: https://digitalcommons.unl.edu/parasitologyfacpubs

Part of the Biodiversity Commons, Evolution Commons, and the Parasitology Commons

\begin{abstract}
Hoberg, Eric P.; Gardner, Scott Lyell; and Campbell, Ronald A., "Systematics of the Eucestoda: Advances Toward a New Phylogenetic Paradigm and Observations on the Early Diversification of Tapeworms and Vertebrates" (1999). Faculty Publications from the Harold W. Manter Laboratory of Parasitology. 56. https://digitalcommons.unl.edu/parasitologyfacpubs/56
\end{abstract}

This Article is brought to you for free and open access by the Parasitology, Harold W. Manter Laboratory of at DigitalCommons@University of Nebraska - Lincoln. It has been accepted for inclusion in Faculty Publications from the Harold W. Manter Laboratory of Parasitology by an authorized administrator of DigitalCommons@University of Nebraska - Lincoln. 
Systematic Parasitology (1999) 42: 1-12.

Copyright 1999, Kluwer Academic Publishers. Used by permission.

\title{
Systematics of the Eucestoda: Advances Toward a New Phylogenetic Paradigm, and Observations on the Early Diversification of Tapeworms and Vertebrates*
}

\author{
Eric P. Hoberg ${ }^{1}$, Scott L. Gardner ${ }^{2} \&$ Ronald A. Campbell ${ }^{3}$

\begin{abstract}
${ }^{1}$ Biosystematics and National Parasite Collection Unit, United States Department of Agriculture, Agricultural Research Service, BARC East No. 1180, 10300 Baltimore Avenue, Beltsville, Maryland 20715, USA (eric.hoberg@ars.usda.gov)

${ }^{2}$ Harold W. Manter Laboratory of Parasitology, W-529 Nebraska Hall, University of Nebraska, Lincoln, Neb. 68588-0514, USA
\end{abstract} \\ ${ }^{3}$ Department of Biology, University of Massachusetts-Dartmouth, N. Dartmouth, Massachusetts 02747, USA
}

Accepted for publication July 9, 1998.

\begin{abstract}
Evolutionary relationships of the Eucestoda have received intense but sporadic attention over the past century. Since 1996, the landscape has dramatically changed with respect to our knowledge of the phylogenetic relationships among the tapeworms. The 2nd International Workshop for Tapeworm Systematics (IWTS) held in Lincoln, Nebraska in October of that year provided the catalyst for development of novel hypotheses for inter-and intra-ordinal phylogeny. The working-group structure of the 2nd IWTS and results of phylogenetic studies are briefly introduced in the present manuscript. Higher-level phylogenies derived from parsimony analysis of independent data bases representing comparative morphology or molecular sequences were largely congruent and supported monophyly for the Eucestoda. The Caryophyllidea are basal; difossate forms such as the Pseudophyllidea are primitive; tetrafossates including the Tetraphyllidea, Proteocephalidea, Nippotaeniidea, Tetrabothriidea and Cyclophyllidea are derived; and hypotheses differed in the placement of the Trypanorhyncha and the Diphyllidea. These studies may provide a foundation for resolution of inter-and intra-ordinal relationships for the tapeworms. Additionally, the first comprehensive phylogenetic hypotheses for the Pseudophyllidea, Diphyllidea, Trypanorhyncha, the paraphyletic Tetraphyllidea + Lecanicephalidea, Proteocephalidea and Cyclophyllidea were developed during and subsequent to the 2nd IWTS. The stage is now set for continued and rapid advances in our understanding of the eucestodes. These studies have also served to re-emphasise the rich genealogical diversity of tapeworms and the temporally deep history for their origin. A co-evolutionary history and radiation of eucestodes may involve deep co-speciation with vertebrate host taxa, accompanied by some level of colonisation and extinction, extending into the Palaeozoic, minimally 350-420 million years ago.
\end{abstract}

\section{Introduction}

Interest in the systematics of the tapeworms has escalated over the past decade. The first phylogenetic study of cestodes, a treatment of the Proteocephalidea Mola, 1928 was published by Brooks (1978) more than 20 years ago, but the number of papers addressing phylogeny, co-evolution and historical

\footnotetext{
* A report of results of phylogenetic analyses conducted during the 2nd International Workshop for Tapeworm Systematics, Lincoln, Nebraska, October 2-6, 1996; E.P. Hoberg, S.L. Gardner and R.A. Campbell, organizers. Contributions edited by E.P.Hoberg.
}

issues related to the Eucestoda Southwell, 1930 has dramatically increased since the late 1980s (see Brooks \& McLennan, 1993; Hoberg et al., 1997b; Hoberg, 1997; Mariaux, 1998). Higher-level relationships among the orders have been examined only recently for the first time (e.g. Brooks et al.,1991; Brooks \& McLennan, 1993), whereas most previous studies focused on species or generic genealogical diversity. Interest in the systematics and taxonomy of tapeworms led to the 1st International Workshop for Tapeworm Systematics (IWTS) chaired 
by Claude Vaucher and Jean Mariaux in Geneva, Switzerland in 1993 (Mariaux \& Vaucher, 1994). At this seminal meeting the conceptual roots were created to build a broad and cooperative international research program addressing significant questions in eucestode systematics.

Evolutionary relationships of the eucestodes have received intense but sporadic attention over the past century, but there has never been a general consensus among the various hypotheses (see Brooks et al., 1991; Mariaux, 1996; Hoberg et al., 1997b). Conflicting opinions over the adequacy of different classes of morphological and molecular characters as indicators of relationship, the application of different methodologies for phylogenetic reconstruction, and untested assumptions of host-parasite co-speciation (e.g. the concept that the phylogeny of hosts mirrors that of the parasite taxon) have contributed to the current situation (Mariaux, 1996). Although the most recent diagnostic keys provided comprehensive coverage to the generic level, there was no general attempt to reflect evolutionary relationships (Khalil et al., 1994). Assessments of phylogenetic diversity, however, have become increasingly important with the advent of biodiversity surveys and inventories in conservation biology, analyses of host-parasite co-speciation and historical biogeography, and strategic research involving agriculturally and medically important taxa (Hoberg, 1997).

These issues formed the foundation for the 2nd IWTS held in Lincoln, Nebraska in 1996 (Hoberg et al., 1997a). The Workshop was convened to explore new and concrete ideas for future progress in tapeworm systematics and to work toward standardising research programmes at the international level with emphasis on phylogenetic systematic analysis (Hennig, 1966; Wiley 1981; Wiley et al., 1991). Results of the Workshop are now summarised in part and presented herein as a series of papers addressing various aspects of eucestode phylogeny.

\section{Methods and rationale}

The structure and rationale for the Workshop (described in detail previously by Hoberg et al., 1997a) are again outlined briefly. The Workshop was novel in attempting to act as a catalyst for development of a synoptic phylogeny for the Eucestoda. Seven working groups, including 38 participants from 19 countries (Appendix 1), were established in October 1995 to represent: (1) relationships at the level of order (chair: E.P. Hoberg); (2) molecular systematics (J. Mariaux); (3) ultrastructural characters of spermatozoa and spermiogenesis (J.-L. Justine); (4) Pseudophyllidea Carus, 1863 (R.A. Bray); (5) Tetraphyllidea Carus, 1863, Trypanorhyncha Diesing, 1863 and associated orders (R.A. Campbell); (6) Proteocephalidea (A. Rego); and (7) Cyclophyllidea van Beneden in Braun, 1900 (A. Jones). Additional groups focused on relationships of genera within families (e.g. Hymenolepididae Ariola, 1899, Anoplocephalidae Cholodkowsky, 1902, Metadilepididae Spasskii, 1959, Paruterinidae Fuhrmann, 1907) and species within genera (e.g. Taeniidae Ludwig, 1886 and species of Taenia Linnaeus, 1758).

Each Working Team produced a summary of characters representing putative homologies for morphological attributes (including those from light and electron microscopy), ontogeny, or molecular sequence data. Putative transformation series generated from character descriptions were polarised relative to taxonomic outgroup(s) (Maddison et al., 1984) and summarised in numerical character matrices. These constituted the basis for development of phylogenetic hypotheses for each taxon under study. Parsimony analyses were conducted with PAUP 3.1.1 and MacClade 3.05 (Swofford, 1993; Maddison \& Maddison, 1992).

Phylogenetic hypotheses resulting from these analyses represented the first concerted effort to develop a comprehensive knowledge of relationships for the Eucestoda. In this context, hierarchical and top-down analyses initially addressed higher level relationships and were in many cases used to identify outgroups for sequential and more inclusive levels of study within orders. In contrast, bottom-up analyses focused on lower taxonomic levels and sampled representative genera and species to estimate phylogenetic structure within and among ordinal-level groups. Thus, an array of characters with different levels of universality (see Wiley, 1981) appropriate to these philosophically disparate but complementary approaches were used in the elucidation of phylogeny. A subsequent step taken by several Working Groups was a preliminary examination of host-parasite cospeciation. 


\section{Results of the workshop}

Higher-level, inter-ordinal phylogeny

Advances in our understanding of the relationships among the currently recognised orders of the Eucestoda were achieved based on independent approaches linked to comparative morphology (Hoberg et al., 1997b), evaluation of spermatozoon ultrastructure and spermiogenesis (Justine, 1998) and analysis of sequence data from $18 S$ rDNA (Mariaux, 1998) (Figures 1,2). Parsimony analysis of morphological and molecular data bases yielded largely congruent trees supporting monophyly for the Eucestoda. Within the Eucestoda, the monozoic Caryophyllidea van Beneden in Carus, 1863 are the basal taxon; difossate forms such as the Pseudophyllidea are regarded as primitive; tetrafossate groups including the paraphyletic "Tetraphyllidea", Lecanicephalidea Baylis, 1920, Proteocephalidea, Nippotaeniidea Yamaguti, 1939, Tetrabothriidea Baer, 1954 and Cyclophyllidea are highly derived. These hypotheses differed in the placement of two taxa, the Trypanorhyncha and Diphyllidea van Beneden in Carus, 1863. Significantly, "total evidence" analysis, now in progress, combining the molecular and morphological data bases resolves the placement of the Trypanorhyncha as depicted in the morphologically based tree (Figure 1) (Hoberg \& Mariaux, unpublished data). Additionally, molecular studies suggest that the Mesocestoididae Perrier, 1897 is the sister-group of the Tetrabothriidea + Cyclophyllidea (Mariaux, 1998). Consequently, the application of comparative data from morphology, ontogeny and ultrastructure is validated and the complementary nature of morphological and molecular approaches is emphasised. As such, these higher-level analyses may form a robust foundation for eventual complete resolution of inter-ordinal phylogeny for the tapeworms. These analyses also serve to highlight the continued problematical nature of relationships among tetrafossates, particularly the coordinate Tetraphyllidea and Lecanicephalidea (Hoberg et al., 1997b; also see Caira et al., 1999); broader interpretations and implications of these studies are presented in Hoberg et al. (1997b), Justine (1998) and Mariaux (1998).

\section{Intra-ordinal phylogeny}

Higher level analyses, briefly outlined above, provided the context and hierarchical basis for more inclusive studies of families, subfamilies and genera within specific orders that are briefly reviewed here and presented in this current issue of Systematic Parasitology. In most instances these represent the first attempt at phylogenetic reconstruction using cladistic methods at the intraordinal level for cestodes. Bray, Jones \& Hoberg (this issue) address the phylogeny of the Pseudophyllidea and examine the structure of the group with respect to subordinal systematics and taxonomy. Beveridge, Campbell \& Palm (this issue) examined the genera of the trypanorhynchs, present a preliminary phylogeny and attempt to evaluate and initiate resolution among the currently competing hypotheses for systematics of the group (e.g. Campbell \& Beveridge, 1994; Palm, 1997). Ivanov \& Hoberg (this volume) examined the problematical Diphyllidea and present a preliminary phylogeny at the species level for this enigmatic group. Rego et al. (1998), presented a robust hypothesis for the Proteocephalidea that supports diagnosis of the subfamilies and monophyly of the Monticelliidae La Rue, 1911; historical biogeographic relationships centring on Gondwanaland are outlined. An hypothesis for relationships among the genera of tetraphyllidean, lecanicephalidean and diphyllidean tapeworms, based on a bottom-up analysis examining representative species and genera, was developed by Caira, Jensen \& Healy (1999); this will be presented in a separate issue of Systematic Parasitology. Finally, the relationships of the families within the Cyclophyllidea were studied by Hoberg, Jones \& Bray (this issue), with the results of this analysis being compared to molecular level investigations by Mariaux (1998).

These series of papers form the core of the results, dealing with inter-and intra-ordinal relationships from the 2nd IWTS. Each presents an historical treatment of a respective group, identification and discussion of characters, phylogenetic reconstruction, comparison with prior explicit phylogenetic hypotheses and in some cases discussion of cospeciation and historical biogeography. Also emphasised are the current gaps in knowledge that impede progress in resolution of phylogeny of the tapeworms and proposals for future studies.

\section{Discussion}

Current state of knowledge

Monophyly for the Eucestoda has been established through a number of studies based on comparative morphology and ultrastructure (e.g. Ehlers, 


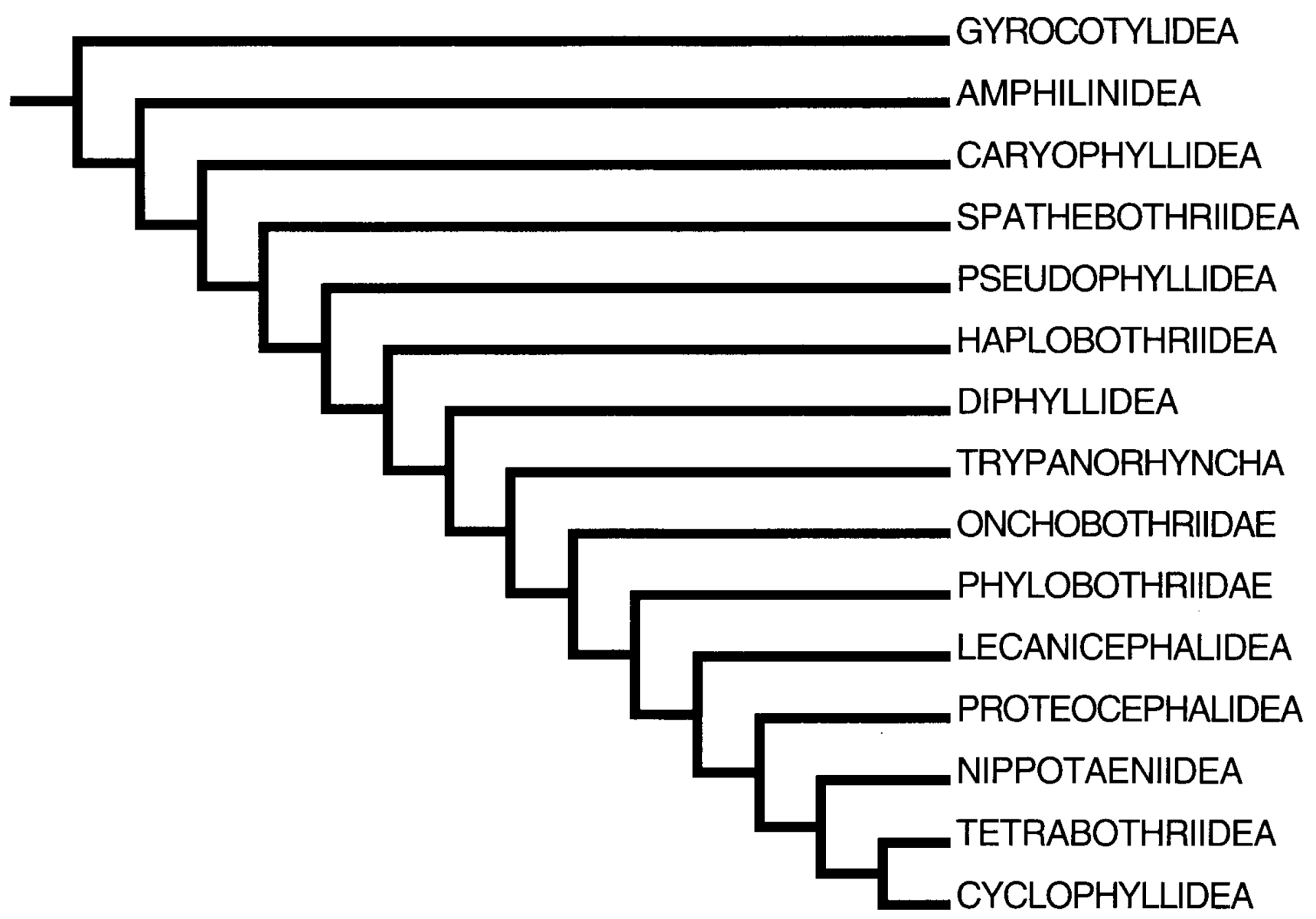

Figure 1. Phylogenetic hypothesis for the orders of the tapeworms derived from comparative morphology (based on Hoberg et al., 1997b). Shown is the single most parsimonious tree, an hypothesis based on 51 transformation series representing binary and multistate characters for 2 outgroups and 12 orders (the Tetraphyllidea is represented by the Phyllobothriidae and Onchobothriidae); Length $=151 ; \mathrm{CI}=0.815$. To reconcile with the results of $18 \mathrm{~s}$ analysis requires 16 additional steps $(\mathrm{CI}=0.74)$.

1985, 1986; Brooks et al., 1985; 1991; Brooks, 1989; Justine, 1991). Starting in 1991, studies began to focus on the relationships within the Eucestoda with the first examination of the phylogenetic structure for the major lineages of the tapeworms (Brooks et al., 1991; Brooks \& McLennan, 1993). Phylogenetic hypotheses for inter-ordinal relationships based on morphology (Hoberg et al., 1997b), ultrastructure (Justine, 1998) and molecular sequence data (Mariaux, 1998) have led to a modification of these recent concepts and earlier ideas that had been developed over the past century (summarised in Hoberg et al., 1997b). Congruence in morphological and molecular approaches exemplified by the current higherlevel analyses suggests that we are converging on a robust understanding of evolutionary relationships among the tapeworms (Figures 1,2). Although estimating the phylogeny of the tapeworms has, in the past, been problematical, we now may be close to resolving the numerous conflicting hypotheses that have been formulated since the 19th century.

Testable hypotheses, based on cladistic analyses, have been presented that are now open to critical examination and further modification (Hoberg et al., 1997b; Caira et al., 1999; Mariaux, 1998). These hypotheses can be used to evaluate the diversity of concepts for relationships that have been presented in the literature and to focus on significant issues related to character evolution. Definitive resolution of higher-level relationships will follow from a continued refinement of databases, inclusion of all orders and broader taxonomic representation in molecular studies, and eventual analysis of total evidence.

Studies based on morphology outlined herein have relied largely on the higher level structure revealed in top-down analysis as the basis for outgroup selection and character polarisation (Hoberg et al., 1997b). In this regard, however, it is critical to 


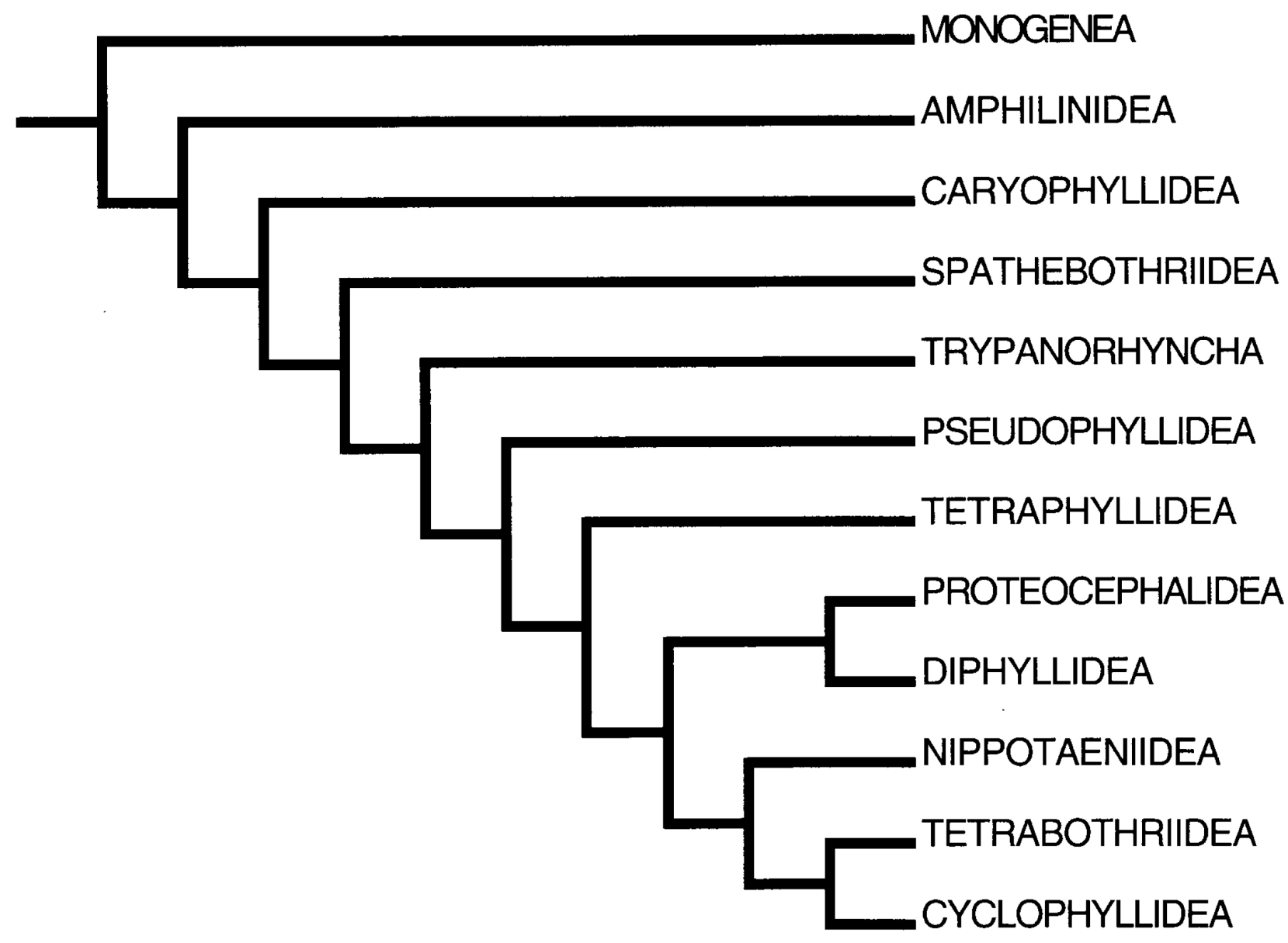

Figure 2. Phylogenetic hypothesis for the orders of the tapeworms derived from an analysis of sequence data representing 188 informative characters (from 1,102 base pairs) of 18S rDNA (based on Mariaux, 1998). Shown is a summary of higher-level relationships derived from a majority rule consensus tree that was based on 480 equal length phylogenetic trees. Included in the analysis were 2 outgroups and 10 orders (Haplobothriidea and Lecanicephalidea are not included) represented by 47 species-level taxa (length $=704$ steps; $C I=0.41)$ (Mariaux, 1998); to reconcile with the results of the analysis based on comparative morphology requires 20 additional steps $(\mathrm{CI}=0.40)$.

note the com plementary nature of top-down versus bottom-up approaches that rely on sampling of representative taxa (e.g. Caira et al., 1999) and to recognise that in both instances the goal is to reconstruct the phylogenetic history for a group. Hypotheses are presented as a potential stimulus for more detailed discussion that embodies a diversity of views and contributions. Phylogenetic resolution has now been obtained for inter-ordinal relationships among the eucestodes. During the 2nd IWTS, hypotheses varying in their degrees of resolution were developed for families, subfamilies or genera among seven of 12 recognised orders (Pseudophyllidea, Diphyllidea, Trypanorhyncha, "Tetraphyllidea", Lecanicephalidea, Proteocephalidea and Cyclophyllidea) (Beveridge et al., 1999; Bray et al., 1999;
Caira et al., 1999; Ivanov \& Hoberg, 1999; Hoberg et al., 1999; Rego et al., 1998). Prior to the Workshop, only the Tetrabothriidea (Hoberg, 1989; Hoberg \& Adams, 1992) and the Proteocephalidea (Brooks, 1978; Brooks \& Rasmussen, 1984) had been evaluated. The Haplobothriidea Joyeux \& Baer, 1961, Nippotaeniidea, Caryophyllidea and Spathebothriidea Wardle \& McLeod, 1952 have yet to be examined in detail with modern phylogenetic methods.

Hopefully, the stage may be set for continued and rapid advances in our understanding of the relationships among the eucestodes. These studies have also served to re-emphasise the rich genealogical diversity of the tapeworms and to raise intriguing questions about their co-evolutionary linkages with vertebrate and invertebrate hosts. 


\section{Higher-level relationships and co-evolution}

It has long been recognised that the tapeworms are an archaic group, and this has been emphasised by concepts for host-parasite associations and the putative role of co-evolution (collectively, co-speciation and co-adaptation, see Brooks \& McLennan, 1991) in the development of groups and assemblages (e.g. Lönnberg, 1897; Fuhrmann, 1931; Wardle \& McLeod, 1952). These studies generally concluded that primitive chondrichthians were hosts for ancestral taxa of eucestodes. Phylogenetically based assessments of eucestode evolution, however, suggested that ancestral groups of tapeworms were parasites in teleost fishes (Brooks et al., 1991; Hoberg et al., 1997b). A more comprehensive examination of this hypothesis (outlined below) may indicate an association with earlier and basal actinopterygian fishes. Discourse, however, on the implications of this observation and the putative age and early radiation of tapeworms in vertebrate host taxa has been limited.

A co-evolutionary history and radiation of the eucestodes may involve temporally deep co-speciation with vertebrate host taxa accompanied by some level of secondary colonisation (e.g. Hoberg et al., 1997b; Hoberg et al., 1999) (Figure 3) and may extend at a minimum into the Palaeozoic, to 350420 million years before present (mybp). Alternatively, some ordinal-level taxa could be younger than this minimum if recent colonisation, in contrast to temporally deep host-switching, has been a dominant force in diversification. Such hypotheses can be evaluated within the context of parasite and host phylogeny, host distribution for parasites, historical biogeography and the fossil record for vertebrates (Brooks \& McLennan, 1993; Hoberg, 1997).

The relationships for the Gyrocotylidea Poche, 1926, Amphilinidea Poche, 1922 and Eucestoda provide the context for elucidating early host-parasite associations. The gyrocotylideans are the sistergroup of the amphilinideans + eucestodes, and the former taxa are recognised as relictual groups that diversified prior to the breakup of Pangea (Bandoni \& Brooks, 1987a,b; Brooks \& Bandoni, 1988). A sister-group relationship for the amphilinideans and tapeworms suggests a minimum age in excess of 200 mybp and indeed, as outlined below, these groups appear to be considerably older, based on assumptions of host-parasite co-speciation at a basal level.

Clear patterns of host-associations are evident relative to the distribution of extant vertebrate and parasite taxa (Figure 3); data for host-distribution are primarily from Schmidt (1986). The gyrocotylideans are restricted to Holocephala among the chondrichthians, whereas the amphilinideans are found in basal actinopterygians (Acipenseridae, sturgeons) and probably secondarily in basal teleosts (e.g. osteoglossomorph fishes) and chelonians; notably the basal species of amphilinideans, Amphilina foliacea (Rudolphi, 1819) and A. japonica Goto \& Ishi, 1936 are parasites in sturgeons (Brooks \& McLennan, 1993). In contrast, members of the basal taxon in the eucestodes, Caryophyllidea, are restricted to families of freshwater teleosts (e.g. the relatively basal Catostomidae, Cyprinidae and Siluriformes). Spathebothriideans are found in sturgeons and teleosts (Salmonidae and Percidae). Pseudophyllideans are found in some actinopterygians (e.g. Marsipometra Cooper, 1917 in the paddlefish Polyodon spathula and Eubothrium Nybelin, 1922 in sturgeons), but principally in marine and freshwater teleosts. The limited presence of some pseudophyllideans in amphibians (Cephalochlamydidae Yamaguti, 1959), chelonians (a species of Triaenophoridae Lönnberg, 1889), lepidosaurians (lizards and snakes), and aquatic birds and mammals (Diphyllobothriidae Lühe, 1902) may represent secondary episodes of colonisation. Haplobothriideans are parasites in the bowfin Amia calva, a neopterygian, basal to the teleosts. The diphyllideans, trypanorhynchs and the paraphyletic assemblage of the tetraphyllideans along with the lecanicephalideans are found exclusively in chondrichthians (Neoselachii, skates, rays and sharks). Proteocephalideans are found principally in Siluriformes (catfishes) but also other relatively basal freshwater teleosts; some proteocephalideans are known in amphibians, chelonians and lepidosaurians (Rego et al., 1998). Nippotaeniideans are parasites in basal teleosts (e.g. galaxids). The sister taxa Tetrabothriidea and Cyclophyllidea are the only groups that predominate in avian and mammalian hosts, although a restricted number of genera and species in the latter are found in amphibians, chelonians and lepidosaurians (Figure 3). Notably, the tetrabothriideans are limited in occurrence in seabirds, pinnipeds and cetaceans. Additionally, the mesocestoidids, a putative relictual group restricted to carnivores, may be the sister group for the Tetrabothriidea + Cyclophyllidea (see Hoberg et al., 1999; Mariaux, 1998).

If basal co-speciation is a viable assumption, we can use this information to infer a minimum age for 


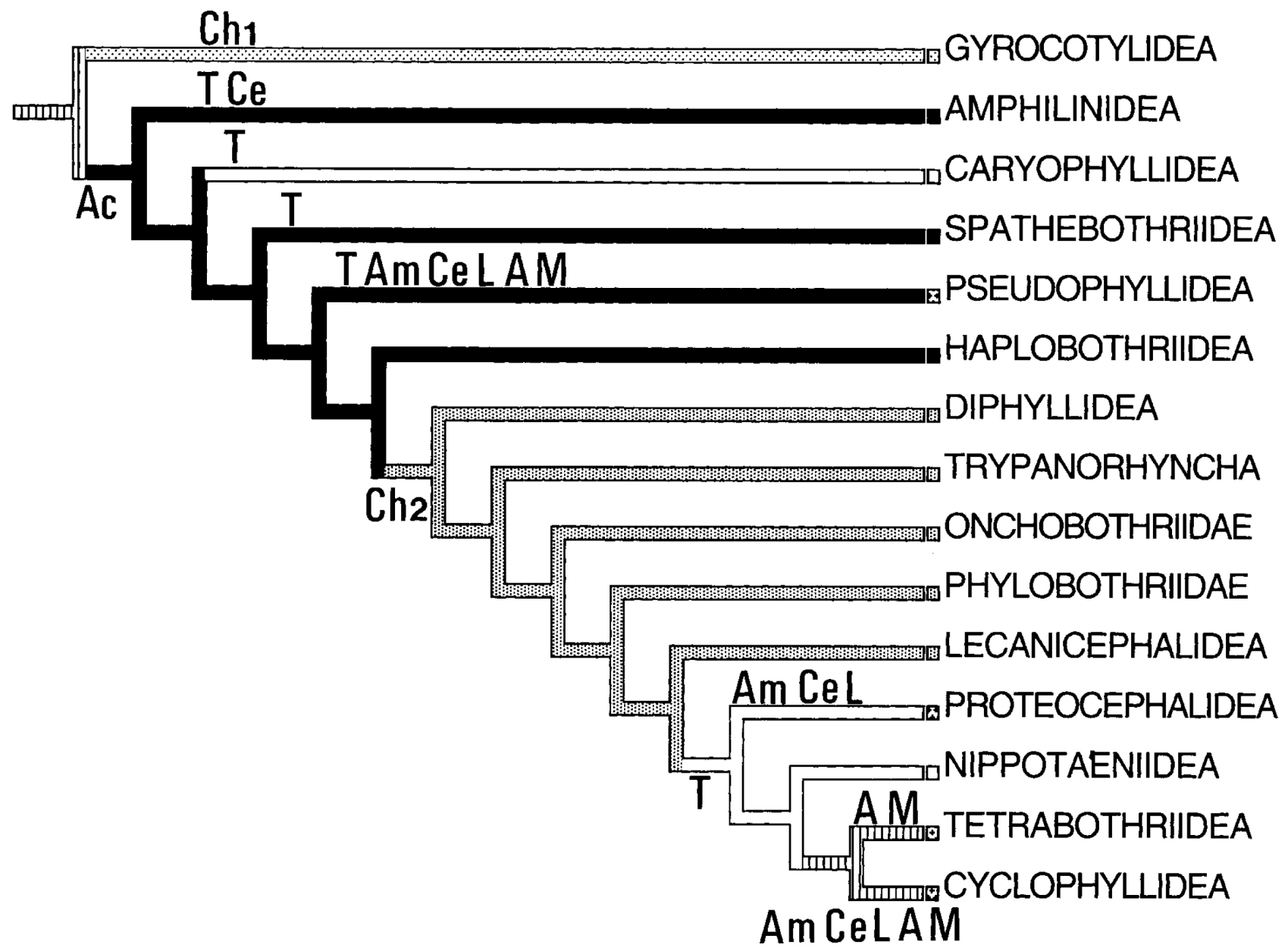

Figure 3. Phylogenetic hypothesis for eucestodes based on comparative morphology, showing the distribution of major vertebrate definitive hosts. Host-taxa were mapped and optimised on the tree representing the complete analysis including all ordinal level taxa, with MacClade 3.05 (Maddison \& Maddison, 1995); CI = 0.94, RI = 0.83. Host distributions are indicative of an early co-evolutionary association with basal actinopterygian fishes, multiple colonisations of relatively basal teleosts, and a secondary colonisation of chondrichthians, compatible with a complex history of co-speciation, host-switching and extinction. Host taxa are as follows: $\mathrm{A}$ = avian groups; $\mathrm{Ac}=$ basal actinopterygians (e.g. sturgeons, the bowfin Amia calva and paddlefish Polyodon spathula); $\mathrm{Am}=$ amphibians; $\mathrm{Ce}=$ chelonians; $\mathrm{Ch1}=$ holocephalans or chimaeras (Chondrichthyes); Ch2 = neoselachians, or sharks, skates and rays (Chondrichthyes); $\mathrm{L}=$ lepidosaurians (snakes and lizards); $\mathrm{M}$ = mammals; and $\mathrm{T}=$ basal teleosts.

the true tapeworms. It must be recognised, however, that origin or basal cladogenesis for a group may be radistinct from secondary radiation within a clade that accounts for currently extant genera and species, and perhaps families. The basal groups of eucestodes, as noted above, are primarily found in basal actinoptery gian and relatively basal teleost fishes; there is no indication based on the parasite phylogeny and mapping of host groups that eucestodes were present in archaic sharks and rays, although gyrocotylideans are present in holocephalans. Cladogenesis leading to the gyrocotylideans and amphilinideans + eucestodes may have coincided with the divergence of placoderms + chondrichthians and lineages leading to the actinopterygians as early as the Devonian 420 mybp. Gyrocotylideans then represent the remnants of a radiation in chondrichthians that ultimately survived in the Holocephala.

In contrast, the amphilinideans + eucestodes apparently diversified initially in primitive rayfinned fishes. This is compatible with the earliest radiation of tapeworms being associated with actinopterygian and neopterygian fishes after 350-400 mybp, in lineages including sturgeons, paddlefish and bowfins, with secondary host switches to basal teleosts, chondrichthians (neoselachians), amphibians and amniotes (see Brooks et al., 1991; Hoberg et al., 1997b) (Figure 3). Colonisation of tetrapods is postulated based on the absence of tapeworms in lobe-fins, such as lung- 
fishes and coelacanths, although this could represent a secondary loss or extinction in these groups.

The chondrichthians + placoderms are the sister group for an assemblage of extinct piscine taxa + actinopterygians; the ray-finned fishes contain the derived teleosts (Long, 1995; Stiassny et al., 1996). The fossil record indicates that initial diversification of the phylogenetically disparate archaic sharks and ray-finned fishes occurred in the Devonian about 410- 420 mybp, with a later radiation of the holocephalans and sturgeons between 250-355 mybp. By the termination of the Permian, 250 mybp, the chimaeras, neoselachians and actinopterygians, represented by the paleoniscoids with lineages leading to the sturgeons, gars, paddlefish and bowfins, are recognised. Teleosts are not represented until the Triassic (after 250 mybp) and all major orders are present by the mid-Cretaceous, covering a span of 100-250 mybp. The basal amphibians are recognized in the late Devonian, and three lineages of amniotes, represented by mammals (synapsids), chelonians and saurian groups (leading to birds), diverged in the upper Carboniferous, 300 mybp; mammals originated in the Triassic at 225 mybp and birds in the mid-Jurassic, 160 mybp (see Carroll, 1988; Dingus \& Rowe, 1998). This provides a minimum putative age for the diversification of eucestodes in vertebrates, assuming a basal association of ancestral tapeworms with actinopterygian fishes, and the basis for examining patterns of development for host-parasite associations.

Ray-finned fishes as the basal hosts for tapeworms suggests that the occurrence of caryophyllideans, spathebothriideans, pseudophyllideans and proteocephalideans + nippotaenideans in teleosts is attributable to colonisation (Figure 3). This contention is further supported by the distribution of these cestodes in relatively basal groups of teleosts (Long, 1995; Lauder \& Wainwright, 1992). Thus, it is postulated that there were four independent episodes of colonisation by eucestodes in freshwater and marine teleostean fishes (Figure 3).

It further suggests that the radiation of tapeworm lineages limited in distribution to contemporary sharks and rays resulted from colonisation via an actinopterygian source early in the diversification of neoselachians to account for the considerable genealogical and ecological diversity observed in such taxa as the trypanorhynchs and "tetraphyllideans" (Figure 3). In this context, the gyrocotylideans in chimaeras appear as relictual remnants of an early radiation in chondrichthians that ul- timately went to extinction. Considering extant eucestode taxa, the phylogenetic position of the diphyllideans and their occurrence largely in skates and rays (Campbell \& Andrade, 1997; Ivanov \& Hoberg, 1999) is compatible with an hypothesis for secondary colonisation and radiation. Such colonisation may have coincided with the radiation of chondrichthians (Neoselachii + Batoidea) that extended from the Devonian into the Mesozoic.

Interestingly, this pattern of association of eucestodes in actinopterygians, teleosteans and chondrichthians appears to be paralleled to some extent by the Digenea and Monogenea. Brooks (1989) suggested that initial diversification of digeneans, monogeneans and cestodarians coincided with the origins and divergence of lineages for chondrichthians and Osteichthyes. Boeger \& Kritsky (1997) have postulated that there was a radiation of monogeneans in early chondrichthians that largely went extinct and that extant groups of parasites in neoselachians represent a colonisation from teleosts. In the case of the Digenea, their sister group, the aspidogastreans, is also relictual, with basal members in chondrichthians and occasionally other aquatic hosts. In contrast to cestodes and monogeneans, very few digeneans have colonised sharks and rays.

The putative great age for eucestodes in basal actinopterygian, teleostean and chondrichthian fishes is further compatible with estimates for the timing of diversification of tapeworms, including the tetrabothriideans and cyclophyllideans, which are dominant respectively in marine and terrestrial birds and mammals (Spasskii, 1993a,b; Hoberg et al., 1999). The postulated ancestor of the tetrabothriideans + cyclophyllideans may have been a parasite in late Palaeozoic or early Mesozoic synapsids or saurians. The distribution in contemporary host groups suggests diversification of tetrabothriideans in now extinct marine saurians (e.g. ichthyosaurs) and non-avian archosaurs (e.g. pterosaurs), early colonisation of seabirds in the late Cretaceous and secondary host-switching to marine mammals in the Tertiary (Hoberg \& Adams, 1992; Spasskii, 1993b; Hoberg et al., 1997b). This would further suggest that the initial diversification of cyclophyllideans occurred in now extinct terrestrial saurians or synapsids during the early Mesozoic, with colonisation or co-evolution in early mammals and colonisation of amphibians after 225 mybp (see Dingus \& Rowe, 1998). In this context, the basal cyclophyllideans are represented by the Mesocestoididae + Nematotaeniidae Lühe, 1910, the latter group having radi- 
ated in gondwanan anurans 180-200 mybp (Jones, 1987; Hoberg et al., 1999). Consequently, the current distribution of these tapeworm taxa may be, in part, related to patterns of colonisation of mammals and birds and extinction of ancestral host lineages during the Mesozoic (Spasskii, 1993a,b; Hoberg et al., 1999).

The depauperate tapeworm faunas or the sporadic occurrence of phylogenetically unrelated cestodes in amphibians, chelonians and lepidosaurians (snakes and lizards) and their absence in lobe-finned fishes (coelacanths and lung fishes) and crocodilians is consistent with an hypothesis for independent colonisation following divergence of respective tetrapod host groups in the Palaeozoic and Mesozoic. This observation is particularly highlighted by the distribution of tapeworms in turtles (Pichelin et al., 1998) and amphibians.

Overall, the patterns of occurrence for cestodes are suggestive of a series of colonisation episodes accompanied by rapid and explosive radiations in fishes (e.g. neoselachians and relatively basal teleosts) and amniotes (e.g. in lineages leading to extant birds and mammals) over short time frames coinciding with the origins of respective host groups. Following an early co-evolutionary history with basal actinopterygians, the temporal duration of these associations potentially extends from the middle to late Palaeozoic and or early Mesozoic into the Tertiary, with the development of specific assemblages being dependent on the timing of host-switching (see Hoberg et al., 1999).

An implication of a deep and complex history for eucestodes is the observation that these groups were persistent across major global extinction events that marked the termination of the Permian 250 mybp and the Cretaceous 65 mybp (Alvarez et al., 1980; Bowring et al., 1998), inclusive in the seven to nine episodes that have been defined for the Phanerozoic (see Briggs, 1995). Lineage persistence may have involved all of the currently recognised orders for the eucestodes. The alternative, which appears less likely, is that major lineages of cestodes originated and radiated subsequent to these extinction events; there is no indication, however, of orders originating subsequent to the Cretaceous-Tertiary boundary.

Assuming the estimate of a middle to late Palaeozoic age for tapeworms is correct, it is apparent from an historical ecological perspective (Brooks, 1985) that faunal assemblages represented by definitive and intermediate hosts and particular tapeworm taxa can serve as indicators of ecological structure and stability during periods of maximal environ- mental perturbation (e.g. Gardner \& Campbell, 1992; Hoberg, 1997; Hoberg et al., 1999). It may be remarkable that tapeworms with complex life-cycles, dependent on phylogenetically disparate vertebrate and invertebrate hosts, were persistent. It is apparent, however, that parasite-host assemblages have tracked across extinction events that may have been of global proportions. Extinction-bottlenecks would have been determinants of parasite diversity relative to elimination of host groups or particular parasite taxa; repeated bottlenecks and secondary radiation for survivors may explain the current patterns of host associations, and genealogical and ecological diversity for eucestodes. Additionally, the distribution of some taxa suggests diversification in synapsids, saurians and non-avian archosaurs that became extinct subsequent to colonisation of now recognised contemporary host groups such as birds and mammals. The implications are apparent for understanding the continuity of ecological structure over evolutionary time frames, within the context that the persistence of parasite lineages is intimately dependent upon host-group survival, and stability of host-parasite assemblages. Thus, cestodes serve to provide the linkage for examining the interaction of co-evolution, colonisation and extinction on the structure of faunas and ecological continuity across deep temporal and geographical scales (Hoberg, 1997; Hoberg et al., 1999).

\section{Conclusions and the future}

Phylogenetic studies of tapeworms derived from the 2nd IWTS place the eucestodes among the bestresolved taxa. Congruence is apparent in comprehensive inter-ordinal hypotheses that have thus far been developed (e.g. Hoberg et al., 1997b; Mariaux, 1998). Phylogenetic assessments for relationships within eight orders have been presented since 1989, with seven new studies being generated from the 2nd IWTS. The stage is set for rapid advances in our understanding of the evolutionary history of the Eucestoda. Progress is dependent on identification of gaps in our knowledge (e.g. Mariaux, 1996), recognition of new characters and new concepts for interpretation, as exemplified by the diverse studies presented in this issue of Systematic Parasitology. The ultimate goal is for resolution of phylogeny based on assessment of total evidence, derived from a diversity of data-sets, including morphological characters and multiple gene systems to achieve new insights based on the applica- 
tion of a unified methodology for analysis. We appear to be in reach of this goal (Hoberg et al., 1997a).

This is a tumultuous time as we approach the end of the 20th Century. We have the opportunity, however, to provide a new, solid foundation and direction for advances in cestode systematics. The 2 nd IWTS has contributed a strong level of continuity for scientific progress, basic research and education. The commitments to the success of the 2nd IWTS on the part of all participants has served to promote continuing advances in understanding tapeworm biodiversity, evolution and elucidation of a complex history for biogeography and co-evolution.

\section{Acknowledgements}

The 2nd IWTS, organised by EPH, SLG and RAC, was held at the Harold W. Manter Laboratory of Parasitology, University of Nebraska-Lincoln 2-6 October 1996, with the theme of promoting a broad-based phylogenetic research programme on cestodes. Thirty-eight scientists representing 19 countries participated, including nearly all current world authorities on cestode taxonomy and character analysis. We sincerely thank the participants who freely shared their knowledge and ideas, over many long hours, resulting in a truly synergistic workshop. We acknowledge the efforts of Niki Gulseth and Mauritz 'Skip' Sterner, of the Harold Manter Laboratory, and Judith Holland of the Biosystematics and National Parasite Collection Unit, in ensuring a productive meeting. The Workshop was generously supported by grants and other resources from the American Society of Parasitologists, Agricultural Research Service (Office of the Director, Beltsville Area Research Center; and BNPCU), University of Nebraska-Lincoln (H.W. Manter Laboratory; and Office of the Chancellor), Foreign Agricultural Service, USDA, the United States Civilian Research and Development Foundation (CRDF) for the Independent States of the Former Soviet Union, Pfizer Inc., and private donations. We also thank Deborah McLennan and Daniel Brooks for critical comments on ideas presented in this manuscript.

\section{References}

Alvarez, L.W., Alvarez, W., Asaro, F. \& Michel, H.V. (1980) Extraterrestrial cause for the Cretaceous-Tertiary extinction. Science, 208, 1,095-1,108.

Bandoni, S.M. \& Brooks, D.R. (1987a) Revision and phylogenetic analysis of the Amphilinidea Poche, 1922 (Platyhelminthes: Cercomeria: Cercomeromor- pha). Canadian Journal of Zoology, 65, 1,110-1,128. Bandoni, S.M. \& Brooks, D.R. (1987b) Revision and phylogenetic analysis of the Gyrocotylidea Poche, 1926 (Platyhelminthes: Cercomeria: Cercomeromorpha). Canadian Journal of Zoology, 65, 2,369-2,389.

Beveridge, I., Campbell, R.A. \& Palm, H.W. (1999) Preliminary cladistic analysis of genera of the cestode order Trypanorhyncha Diesing, 1863. Systematic Parasitology, 42, 22-49.

Boeger, W.A. \& Kritsky, D.C. (1997) Coevolution of the Monogenoidea (Platyhelminthes) based on a revised hypothesis of parasite phylogeny. International Journal for Parasitology, 27, 1,495-1,511.

Bowring, S.A., Erwin, D.H., Jin, Y.G., Martin, M.W., Davidek, K. \& Wang, W. (1998) U/Pb zircon geochronology and tempo of the end-Permian mass extinction. Science, 280, 1,039-1,048.

Bray, R.A., Jones, A. \& Hoberg, E.P. (1999) Observations on the phylogeny of the cestode order Pseudophyllidea Carus, 1863. Systematic Parasitology, 42, 13-20.

Briggs, J.C. (1995) Global Biogeography. New York: Elsevier, 452 pp.

Brooks, D.R. (1978) Evolutionary history of the cestode order Proteocephalidea. Systematic Zoology, 27, 312-323.

Brooks, D.R. (1985) Historical ecology: a new approach to studying the evolution of ecological associations. Annals of the Missouri Botanical Garden, 72, 660-680.

Brooks, D.R. (1989) A summary of the database pertaining to the phylogenyofthemajorgroupsofparasiticplatyhelminthes, with a revised classification. Canadian Journal of Zoology, 67, 714- 720.

Brooks, D.R. \& Bandoni, S.M. (1988) Coevolution and relicts. Systematic Zoology, 37, 19-33.

Brooks, D.R., Hoberg, E.P. \& Weekes, P.J. (1991) Preliminary phylogenetic systematic analysis of the major lineages of the Eucestoda (Platyhelminthes: Cercomeria). Proceedings of the Biological Society of Washington, 104, 651-668.

Brooks, D.R. \& McLennan, D.A. (1991) Phylogeny, Ecology and Behavior: A Research Program in Comparative Biology. Chicago: University of Chicago Press, 434 pp.

Brooks, D.R. \& McLennan, D.A. (1993) Parascript Parasites and the Language of Evolution. Washington, DC: Smithsonian Institution Press, 429 pp.

Brooks, D.R., O'Grady, R.T. \& Glenn, D.R. (1985) The phylogeny of the Cercomeria Brooks, 1982 (Platyhelminthes). Proceedings of the Helminthological Society of Washington, 52, 1-20.

Brooks, D.R. \& Rasmussen, G. (1984)Proteocephalid cestodes from Venezuelan catfish, with a new classification of the Monticelliidae. Proceedings of the Biological Society of Washington, 97,748-760.

Caira, J.N., Jensen, K. \& Healy, C.J. (1999) On the phylogenetic relationships among the tetraphyllidean, lecanicephalidean, and diphyllidean tapeworm genera. Systematic Parasitology, 42, 77-151.

Campbell, R.A. \& Andrade, M. (1997) Echinobothrium raschii n. sp. (Cestoda: Diphyllidea) from Rhinoraja longi (Chondrichthyes: Rajoidei) in the Bering Sea. Journal of Parasitology, 83, 115-120.

Campbell, R.A. \& Beveridge, I. (1994) Order Trypanorhyncha Diesing, 1863. In: Khalil, L.F., Jones, A. \& Bray, R.A. (Eds) Keys to the Cestode Parasites of Vertebrates. Wallingford, UK: CAB International, pp. 51-148.

Carroll, R.L. (1988) Vertebrate Paleontology and Evolution. New York: W. H. Freeman, 698 pp.

Dingus, L. \& Rowe, T. (1998) The Mistaken Extinction, Dinosaur Evolution and the Origin of Birds. New York: W.H. Freeman, 332 pp.

Ehlers, U. (1985) Phylogenetic relationships among the Platyhelminthes. In: Morris, C., George, J.D., Gibson, R. \& Platt, 
H.M. (Eds), The Origins and Relationships of Lower Invertebrates. Oxford, UK: Oxford University Press, pp. 143-158. Ehlers, U. (1986) Comments on a phylogenetic system of the Platyhelminthes. Hydrobiologia, 132, 1-12.

Fuhrmann, O. (1931) Dritte Klasse des Cladus Platyhelminthes. Cestoidea. In: Kukenthal, W. (Ed.) Handbuch der Zoologie.Vol. 2. Berlin: Kukenthal und Krumbach, pp. 141-416.

Hennig, W. (1966) Phylogenetic Systematics. Urbana, Illinois: University of Illinois Press, 263 pp.

Gardner, S.L. \& Campbell, M.L. (1992) Parasites as probes for biodiversity. Journal of Parasitology, 78, 596-600.

Hoberg, E.P. (1989) Phylogenetic relationships among the genera of the Tetrabothriidae (Eucestoda). Journal of Parasitology, 75, 617-626.

Hoberg, E.P. (1997) Phylogeny and historical reconstruction: Host parasite systems as keystones in biogeography and ecology. In: Reaka-Kudla, M.L., Wilson, D. \& Wilson, E.O. (Eds) Biodiversity II: Understanding and Protecting Our Biological Resources. Washington, DC: Joseph Henry Press, National Academy of Sciences, pp. 243-261.

Hoberg,E.P.\&Adams, A. (1992)Phylogeny and historical biogeography and ecology of Anophryocephalus spp (Eucestoda: Tetrabothriidae) among pinnipeds of the Holarctic during the late Tertiary and Pleistocene. Canadian JournalofZoology, 70,703-719.

Hoberg, E.P., Gardner, S.L. \& Campbell, R.A. (1997a) Paradigm shiftsand tapewormsystematics.Parasitology Today,13,161-162.

Hoberg, E.P., Jones, A. \& Bray, R.A. (1999) Phylogenetic analysis among the families of the Cyclophyllidea (Eucestoda) based on comparative morphology, with new hypotheses for coevolution in vertebrates. Systematic Parasitology, 42, 51-73.

Hoberg, E.P., Mariaux, J., Justine, J.-L., Brooks, D.R. \& Weekes, P.J. (1997b) Phylogeny of the orders of the Eucestoda (Cercomeromorphae) based on comparative morphology: historical perspectives and a new working hypothesis. Journal of Parasitology, 83, 1,128-1,147.

Ivanov, V. \& Hoberg, E.P. (1999) Preliminary comments on a phylogenetic study of the order Diphyllidea van Beneden in Carus, 1863. Systematic Parasitology, 42, 21-27.

Jones, M.K. (1987) A taxonomic revision of the Nematotaeniidae Lühe, 1910 (Cestoda: Cyclophyllidea). Systematic Parasitology, 10, 165-245.

Justine, J.-L. (1991) Phylogeny of parasitic Platyhelminthes: a critical study of synapomorphies proposed on the basis of the ultrastructure of spermiogenesis and sperm. Canadian Journal of Zoology, 69, 1,421-1,440.

Justine, J.-L. (1998) Spermatozoa as phylogenetic characters for the Eucestoda. Journal of Parasitology, 84, 385-408.

Khalil,L.F.,Jones, A.\&Bray, R.A.(Eds) (1994) Keys to the CestodeParasites of Vertebrates. Wallingford, UK: CAB International,751 pp.

Lauder, G.V. \& Wainwright, P.C. (1992) Function and history: the pharyngeal jaw apparatus in primitive rayfinned fishes. In: Mayden, R.L. (Ed.) Systematics, Historical Ecology, and North American Freshwater Fishes. Stanford, CA: Stanford University Press, pp. 455-471.

Lönnberg, E. (1897) Beitrage zur Phylogenie der Platyhelminthen. Centralblatt Bakteriologie Parasitenkunde und Infektionkrankheiten, 21, 674-684.

Long, J.A. (1995) The Rise of Fishes: 500 Million Years of Evolution. Baltimore: Johns Hopkins University Press, 223 pp.

Maddison, W.P., Donoghue, M.J. \& Maddison, D.R. (1984) Outgroup analysis and parsimony. Systematic Zoology, 33, 83-103.
Maddison, W.P. \& Maddison, D.R. (1995) MacClade: Analysis of Phylogeny and Character Evolution. Version 3.05. Sunderland, Massachusetts: Sinauer \& Associates. Mariaux, J. (1996) Cestode systematics: any progress? International Journal for Parasitology, 26, 231-243.

Mariaux, J. (1998) A molecular phylogeny of the Eucestoda. Journal of Parasitology, 84, 114-124.

Mariaux, J. \& Vaucher, C. (1994) Progress in tapeworm systematics. Parasitology Today, 10, 43-44.

Palm, H. (1997) An alternative classification of trypanorhynch cestodes considering the tentacular armature as being of limited importance. Systematic Parasitology, 37, 81-92.

Pichelin, S., Cribb, T.H. \& Bona, F.V. (1998) Glossocercus chelodinae (MacCallum, 1921) n. comb. (Cestoda: Dilepididae) from freshwater turtles in Australia and a redefinition of the genus Bancroftiella Johnston, 1911. Systematic Parasitology, 39, 165-181.

Rego, A.A., de Chambrier, A., Hanzelova, V., Hoberg, E., Scholz, T., Weekes, P. \& Zehnder, M. (1998) Preliminary phylogenetic analysis of subfamilies of the Proteocephalidea (Eucestoda). Systematic Parasitology, 40, 1-19.

Schmidt, G.D. (1986) CRC Handbook of Tapeworm Identification. Boca Raton: CRC Press, 675 pp.

Spasskii, A.A. (1993a) [On the cestode fauna of the Mesozoic terrestrial dinosaurs.] Conference XI, Ukrainian Society of Parasitologists, Kiev. Tezisy Dokladov, pp. 152-153. (In Russian; English translation by V. Tkach).

Spasskii, A.A. (1993b) [On the participation of the marine Mesozoic reptiles in the evolution of the suborder Tetrabothriata (Cestoda: Tetraphyllidea).] Conference XI, Ukrainian Society of Parasitologists, Kiev. Tezisy Dokladov, pp. 153-154. (In Russian; English translation by V. Tkach).

Stiassny, M.L.J., Parenti, L. \& Johnson, G.D. (Eds) (1996) The Interrelationships of Fishes. New York: Academic Press, 496 pp.

Swofford,D.L.(1993)PAUP:PhylogeneticAnalysis Using Parsimony. Version 3.1.1. Champaign, Ill.: Illinois Natural History Survey.

Wardle, R.A. \& McLeod, A.J. (1952) The Zoology of Tapeworms. Minneapolis: University of Minnesota Press, $780 \mathrm{pp}$.

Wiley, E.O. (1981) Phylogenetics: The Principles and Practice of Phylogenetic Systematics. New York: John Wiley \& Sons, 439 pp.

Wiley, E.O., Siegel-Causey, D., Brooks, D.R. \& Funk, V. (1991) The Compleat Cladist: a Primer of Phylogenetic Procedures. Lawrence, Kansas:UniversityofKansasMuseumofNaturalHistory,158pp.

\section{Appendix 1}

Participants in the Second International Workshop for Tapeworm Systematics, listing national affiliation and area of expertise.

Australia: Ian Beveridge (Cyclophyllidea - Anoplocephalidae; Tetraphyllidea; Trypanorhyncha). Argentina: Veronica Ivanov (Tetraphyllidea; Diphyllidea. Brazil: Amilcar Rego (Proteocephalidea - working group chair). Bulgaria: Boyko Georgiev (Cyclophyllidea, Metadilepididae, Paruterinidae 
- working group chair). Canada: Daniel Brooks ${ }^{1}$ (higher-level systematics). Czech Republic: Tomas Scholz (Proteocephalidea). France: Louis Euzet (Tetraphyllidea; higher-level cestode systematics). JeanLou Justine (ultrastructural characters, spermatozoons - working group chair). Germany: Harry Palm (Trypanorhyncha). Italy: Franco Bona (Cyclophyllidea, Dilepididae). Korea: Keeseon S. Eom (Taeniidae). Lithuania: Svetlana Bondarenko (Cyclophyllidea, Hymenolepididae). New Zealand: Peter Weekes (higher-level systematics; Nippotaeniidea; Proteocephalidea). Poland: Peter Swiderski ${ }^{1}$ (ultrastructural characters). Russia: Vladimir D. Gulyaev ${ }^{1}$ (higher level systematics; Cyclophyllidea). Slovak Republic: Vladimira Hanzelova (Proteocephalidea). Ivica Kraloval ${ }^{2}$ (Proteocephalidea; molecular systematics). Switzerland: Jean Mariaux (molecular systematics - working group chair; higher-level systematics; Cyclophyllidea, Dilepididae). Claude Vaucher (Cyclophyllidea, Hymenolepididae-working group chair). Alain de Chambrier (Proteo- cephalidea). Marc Zehnder ${ }^{2}$ (molecular systematics; Proteocephalidea). Ukraine: Vadim Korniushin (Cyclophyllidea, Metadilepididae, Paruterinidae, Hymenolepididae). Vasilij Tkach (Cyclophyllidea, Hymenolepididae). United Kingdom: Rodney Bray (Pseudophyllidea - working group chair; Cyclophyllidea). Arlene Jones (Cyclophyllidea - working group chair; Pseudophyllidea). United States: Eric P. Hoberg (higher level systematics - working group chair; Tetrabothriidea; Cyclophyllidea, Taeniidae). Scott Gardner (Cyclophyllidea, Hymenolepididae - working group chair). Robert Rausch (Cyclophyllidea, Taeniidae). Robin Overstreet (Tetraphyllidea). Janine Caira (Tetraphyllidea). Tim Ruhnke (Tetraphyllidea). Ronald Campbell (Tetraphyllidea; Lecanicephalidea; associated orders - working group chair; Trypanorhyncha). Peter Olson ${ }^{2}$ (molecular systematics). Tom Mattis (Tetraphyllidea). Claire Healy $^{2}$ (Tetraphyllidea). Kirsten Jensen ${ }^{2}$ (Tetraphyllidea). Gaines Tyler ${ }^{2}$ (Tetraphyllidea). Mariel Campbell (Cyclophyllidea, Anoplocephalidae).
${ }^{1}$ Corresponded with Working Group, but could not attend Workshop.
${ }^{2}$ Graduate student observer/participant. 